\title{
A função socioambiental da propriedade: outro paradigma
}

O princípio da função social da propriedade, além dos aspectos econômicos e sociais (em sentido estrito), apresenta uma feição ambiental. O presente trabalho promoveu uma revisão da bibliografia sobre o tema, tendo como cerne a construção desta relação de implicação entre os aspectos dominial e ambiental. A partir de uma narrativa histórica e jurídica, na qual foram consideradas as contribuições de Aristóteles, John Locke, Jean-Jacques Rosseau, Fustel de Coulages, Friedrich Engels, Karl Marx, Émile Durkheim e Léon Duguit, descreveu-se como a propriedade foi constituída inicialmente como direito de caráter individual, bem como o seu processo de conversão em instituto jurídico condicionado a uma função social. Levando em conta o advento da crise ambiental moderna, notadamente em razão de suas repercussões para o tema em exame, analisou-se, a partir da obra de Enrique Leff, a importância de introduzir a noção de sustentabilidade como condicionante à função social da propriedade, sendo manifestada adesão à necessidade de considerar uma nova feição, inclusive formal, ao princípio em comento, a fim de designá-lo de função socioambiental da propriedade. Nesse mister, essa providência foi apontada não apenas como uma questão de nomenclatura, mas como de caráter simbólico, destinada a reforçar a relevância e urgência de se conferir a devida atenção às questões ambientais.

Palavras-chave: Propriedade; Função social; Ambiente; Condicionante; Sustentabilidade.

\section{The socio-environmental function of property: another paradigm}

The principle of the social function of property, in addition to the economic and social aspects (in the strict sense), has an environmental feature. The present work promoted a review of the bibliography on the subject, having as its core the construction of this implication relationship between the dominial and environmental aspects. From a historical and legal narrative, in which the contributions of Aristotle, John Locke, Jean-Jacques Rosseau, Fustel de Coulages, Friedrich Engels, Karl Marx, Emile Durkheim and Leon Duguit were considered, it was described how property was constituted. initially as an individual right, as well as its process of conversion into a legal institute conditioned to a social function. Taking into account the advent of the modern environmental crisis, notably due to its repercussions for the theme under consideration, it was analyzed, from Enrique Leff's work, the importance of introducing the notion of sustainability as conditioning to the social function of property, adherence to the need to consider a new feature, including formal, to the principle under consideration, in order to designate it as the socio-environmental function of property. In this sense, this measure was pointed not only as a matter of nomenclature, but as a symbolic character, intended to reinforce the relevance and urgency of giving due attention to environmental issues.

Keywords: Property; Social role; Environment; Conditioning; Sustainability.

Topic: Legislação e Direito Ambiental

Reviewed anonymously in the process of blind peer.
Received: 30/06/2019

Approved: 31/07/2019
Fernando Lopes Dantas (iD)

Universidade Federal de Sergipe, Brasil

http://lattes.cnpq.br/9728026163476188

http://orcid.org/0000-0002-8255-1038

fernando.lopes.dantas@gmail.com

Gicélia Mendes Silva (iD

Universidade Federal de Sergipe, Brasil

http://lattes.cnpq.br/2858199391215049

http://orcid.org/0000-0001-7942-9042

giceliamendes.ufs@gmail.com

\section{Referencing this:}

DANTAS, F. L.; SILVA, G. M.. A função socioambiental da propriedade: outro paradigma. Revista Ibero-Americana de Ciências Ambientais, v.10, n.4, p.385-395, 2019. DOI: http://doi.org/10.6008/CBPC2179$\underline{6858.2019 .004 .0030}$

DOI: $10.6008 / C B P C 2179-6858.2019 .004 .0030$ 


\section{INTRODUÇÃO}

A propriedade sempre demandou e recebeu reflexões por parte de profetas, filósofos, juristas e sociólogos, desde a antiguidade até a atualidade, de modo que as discussões a respeito dessa temática ensejaram a produção de bibliografia que é deveras substancial quanto ao número e significativamente abrangente quanto às abordagens, o que recomenda uma precisa limitação do objeto de estudo, sob pena de se comprometerem os resultados da pesquisa pelo vício da superficialidade, ou de inviabilizar seu resultado pelo excesso de fontes de consulta. Firmada essa premissa, importa assinalar que o exame que aqui se inicia se cingirá à trajetória histórica do instituto da propriedade no mundo ocidental, atentando-se às questões relativas ao seu fundamento e ao regime jurídico no Brasil, conferindo-se especial atenção aos elementos condicionantes ao exercício do direito de propriedade, notadamente da propriedade imobiliária.

Consignadas as advertências necessárias, quanto à delimitação do objeto do presente artigo, impõese afirmar que a propriedade será aqui tratada como "o direito que a pessoa física ou jurídica tem, dentro dos limites normativos, de usar, gozar e dispor de um bem, corpóreo ou incorpóreo, bem como de reivindicar de quem injustamente o detenha" (DINIZ, 2004). Desnecessário, a propósito, dispensar maiores delongas para justificar a adesão a esse conceito de propriedade, bastando assinalar que ele se encontra em conformidade com a atual disciplina normativa desse instituto no Brasil, nos termos do que dispõe o caput do art. $1.228^{1}$ do Código Civil. A propriedade consubstancia, destarte, um vínculo jurídico entre o proprietário e a coisa, mas que repercute também em relação aos que não são proprietários, na medida em que assegura àquele o direito de reivindicar seu bem dos que eventualmente o detenham de forma indevida.

Ao lado dessa prerrogativa conferida ao proprietário, é também a este imposta a obrigação de exercer seu direito 'em consonância com suas finalidades econômicas e sociais e de modo que sejam preservados, de conformidade com o estabelecido em lei especial, a flora, a fauna as belezas naturais, o equilíbrio ecológico e o patrimônio histórico e artístico, bem como evitada a poluição do ar e das águas'². Essa ideia de limites normativos materializaria o preceito estabelecido no art. 5o, inciso XXIII, da Constituição de 1988, que ordena que o exercício do direito de propriedade deve atender à sua função social.

Esse conceito de propriedade, concebido como um direito individual, mas, notadamente, como um direito condicionado a uma função socioambiental, é resultado de um longo itinerário de influências de diversos campos de saber, até que se chegasse a essa configuração. O presente artigo, destarte, pretende revisar (parte de) a bibliografia sobre o tema, com atenção à formação do conceito de propriedade consagrado pelo direito brasileiro, especialmente o estabelecido em conformidade com a Constituição de 1988, que manifestamente vinculou as questões dominial e ambiental. Importa e se impõe, portanto, conhecer essa trajetória histórica e normativa, a fim de evidenciar como a propriedade como direito implica e é também implicada pelos aspectos relacionados ao ('meio') ambiente.

\footnotetext{
${ }^{1}$ Art. 1.228. O proprietário tem a faculdade de usar, gozar e dispor da coisa, e o direito de reavê-la do poder de quem quer que injustamente a possua ou detenha'.

${ }^{2} \mathrm{O}$ trecho transcrito corresponde ao $\S 1$ do art. 1.228 do Código Civil.
} 


\section{METODOLOGIA}

Conforme anunciado, o presente trabalho consiste numa revisão bibliográfica sobre a trajetória da propriedade, com o escopo de realçar a elaboração e constitucionalização do princípio da função socioambiental da propriedade. Em razão disso, a metodologia empregada na pesquisa foi eminentemente bibliográfica (SEVERINO, 2016), pois aqui se examinam os registros históricos e a doutrina jurídica em relação ao direito de propriedade e seus condicionamentos, sobretudo os de caráter ambiental.

Ademais, como o intento do escrito é tornar evidente a vinculação das questões dominiais e ambientais, optou-se por uma revisão predominantemente narrativa, ou seja, que se destina a apresentar o estado da arte sobre em relação a determinado tema (ROTHER, 2007). Nada obstante, essa narrativa foi temperada com alguns traços de sistematicidade, na medida em que se pretendeu demonstrar a existência daquela vinculação, que se consubstanciou na (re)elaboração do princípio da função socioambiental da propriedade, consagrada na Constituição de 1988.

Observando-se o recorte temático acima indicado, e no que concerne à seleção de fontes de pesquisa para o tema propriedade e função social, o trabalho foi desenvolvimento essencialmente a partir da obra de John Locke (Segundo Tratado sobre o Governo), Thomas Hobbes (O Leviatã), Jean-Jacques Rousseau (Do contrato social), Fustel de Coulages (A cidade antiga), Karl Marx (Manifesto do Partido Comunista e Manuscritos econômico-filosóficos), Friedrich Engels (Manifesto do Partido Comunista e A origem da família, da propriedade privada e do Estado), Émile Durkheim (Da divisão do trabalho social, As regras do método sociológico e Lições de Sociologia) e Léon Duguit (Fundamentos do Direito).

Já quanto aos temas relacionados à questão ambiental, a principal fonte da pesquisa foi a obra de Enrique Leff, notadamente seu livro Racionalidade Ambiental. Em relação à disciplina normativa da propriedade e do ('meio') ambiente, optou-se pelo exame direto do texto das Constituições brasileiras, desde a de 1824, até se chegar à promulgada em 5 de outubro de 1988.

No que concerne à estrutura, além da anterior Introdução e deste tópico de Metodologia, este escrito, no tópico destinado à Discussão Teórica, contém dois tópicos de desenvolvimento, sendo ultimado com a apresentação de algumas Conclusões. O primeiro dos tópicos de desenvolvimento se destinou à feitura de uma sintética trajetória histórica da propriedade, que enfatizou as modificações relacionadas ao seu fundamento e condições de exercício.

Em seguida, tratou-se da apresentação da disciplina dada ao tema pelas Constituições brasileiras, centrando-se a análise no direito de propriedade (imobiliária) e sua vinculação aos aspectos ambientais. Por fim, cuidou-se de arrematar este artigo com o reforço da necessidade de evidenciar a existência dessa vinculação, que impõe a atenção ao ambiente como condicionante constitucional ao exercício do direito de propriedade.

\section{DISCUSSÃO TEÓRICA}

A trajetória histórica do direito de propriedade: da inexistência ao direito como função 
Recorrendo-se a Coulanges (2009) para iniciar a descrição dessa trajetória, convém registrar que, segundo o relato de Coulanges (2009), havia uma relação manifesta e indissociável entre a religião doméstica, a família e o direito de propriedade. Referindo-se a costumes que remontavam ao período anterior à antiguidade clássica, o historiador francês apontou que a afetação determinados espaços físicos ao exercício do culto religioso doméstico e ao sepultamento dos mortos de uma família, terminou por converter esses lugares ao uso exclusivo por determinada família, à qual era outorgado, por uma ordem sagrada superior e em caráter perpétuo, o direito de propriedade.

A propriedade privada surge, assim, com fundamento em preceitos de caráter religioso, que autorizavam aquela instituição (família) a se apropriar de certa porção de terra. Essa noção de propriedade como espaço sagrado terminou como conferir um grau de proteção que autorizou muitos a sustentarem que a propriedade se constituiria um direito de caráter absoluto 3 .

Para Locke (2002), a religião também teria estreita relação com o direito de propriedade, sustentando o filósofo inglês que Deus teria concedido coletivamente a todos os homens o mundo e tudo o que este contém. No entanto, ao expedir o comando para que o homem exercesse o domínio sobre esses bens, o próprio Deus também teria autorizado a apropriação individual de parte do que havia sido conferido a todos, estabelecendo, contudo, como medida para essa apropriação a possibilidade de transformação da terra pelo trabalho de cada indivíduo. Sobre essa questão, oportuno se recorrer ao que disse o próprio Locke (2002).

Embora a Terra e todas os seus frutos sejam propriedade comum a todos os homens, cada homem tem uma propriedade particular em sua própria pessoa; a esta ninguém tem qualquer direito senão ele mesmo. $O$ trabalho de seu corpo e a obra das suas mãos, podese afirmar, são propriedade dele. Seja o que for que ele retire da natureza no estado em que the forneceu o no qual o deixou, mistura-se e superpõe-se ao próprio trabalho, acrescentando-lhe algo que pertence ao homem e, por isso mesmo, tornando-o propriedade dele. Retirando-o do estado comum em que a natureza o colocou, agregou-lhe com seu trabalho um valor que o exclui do direito comum de outros homens. Uma vez que esse trabalho é de propriedade exclusiva do trabalhador, nenhum outro homem tem direito ao que foi agregado, pelo menos quando houver bastante e também de boa qualidade em comum para os demais.

Como resulta claro dessa passagem, para Locke, a concessão divina da propriedade cingia-se aos bens no estado de natureza, que assim pertenceriam a todos coletivamente. $\mathrm{O}$ trabalho do homem, de outro modo, é que seria o fundamento legitimo para apropriação da terra e constituição da propriedade privada, sobre a qual o seu detentor exerceria domínio com caráter exclusivo e absoluto.

Essa concepção de Locke contrariava o pensamento de Hobbes (1999) no que concerne à natureza do direito de propriedade. Para Hobbes (1999), o direito de propriedade seria conferido e regulado a partir de prescrições expedidas pelo soberano de determinado Estado, e não como decorrência de uma ordem transcendental. Seriam as leis civis, e não o direito natural, que estabeleceriam o regime jurídico da propriedade.

\footnotetext{
${ }^{3}$ Termina sendo, em certa medida, paradoxal a afirmação de que o direito de propriedade possuiria caráter absoluto. Se a noção de direito pressupõe uma ordem que o justifica, logicamente não pode ser considerado absoluto, já que seria dependente da conformidade com essa mesma ordem. Entenda-se, portanto, um direito "absoluto" de propriedade como aquele em que as possibilidades de intervenção estatal são sobremaneira limitadas e excepcionais.
} 
Rousseau (2013), tal como Hobbes, que sustentava que a constituição do Estado, fundado a partir de um contrato social, seria pressuposto para garantia adequada ao exercício do direito de propriedade, condição inviável de ser obtida antes de serem os homens retirados do estado de natureza. No entanto, Rousseau (2013) divergia de Hobbes (1999) quanto a um aspecto essencial: enquanto para Hobbes o soberano seria a figura central desse pacto, Rousseau (2013) colocava nessa condição o próprio pacto e, ainda, o Estado civil dele decorrente, sendo este último o fundamento para o exercício de qualquer direito.

Com o advento dos movimentos constitucionais do século XVIII, catalisados pelas revoluções Americana (1776) e Francesa (1789), e que foram fortemente influenciados por ideais lluministas, a propriedade foi elevada à condição de direito 'inviolável e sagrado' ${ }^{4}$. E com a ideia de limitação dos poderes do Estado, que passa a se submeter (e não apenas de submeter os súditos) a um ordenamento jurídicoconstitucional, aquele ente (o Estado) se coloca na condição de garantidor primeiro da propriedade privada, a qual é eleita, ao lado da liberdade, da segurança e da resistência à opressão, como um dos valores elementares da sociedade.

Se por um lado a concepção de Estado constitucional passa a conferir a necessária proteção ao direito de propriedade, notadamente em face do próprio Estado, por outro aqueles mesmos ideais Iluministas de liberdade terminariam por reforçar o caráter individual do instituto, de modo que Dallari chega mencionar a existência de um "culto da propriedade individual" (DALLARI, 2010). As incoerências ${ }^{5}$ do modelo liberal Clássico de Estado, que proclamava o prestígio de valores como "liberdade, igualdade e fraternidade", mas se matinha afastado das questões sociais, terminaram por revelar a impossibilidade de um modelo de Estado gendarme alcançar os fins para os quais tal agrupamento social foi instituído: estabelecer o primado da justiça (ROUSSEAU, 2013).

A propósito dessa questão, Engels (2002) afirma que o Estado de então outorgava proteção aos indivíduos levando em conta critérios censitários, constituindo-se, na verdade, em "um organismo para proteção dos que possuem contra os que não possuem." Numa crítica contundente à propriedade privada, Engels (2002), ao lado de Marx (2014), sustentava que "os comunistas podem resumir sua teoria numa expressão: supressão da propriedade privada", apresentando como justificativa para essa necessidade o fato de que, na prática, a maior parte da população já se encontraria excluída do uso e gozo de qualquer propriedade, conforme se pode extrair do trecho do Manifesto do Partido Comunista (MARX et al., 2014).

Horrorizai-vos porque nós queremos abolir a propriedade privada. Mas em vossa sociedade a propriedade privada foi suprimida para nove décimos de seus membros; ela existe precisamente por não existir para nove décimos. Portanto, censurai-nos porque nós queremos suprimir uma propriedade que tem como pressuposto a falta de propriedade para a grande maioria da sociedade.

O fundamento para essa posição se sustentava na alegação de que a propriedade teria perdido, já

\footnotetext{
${ }^{4} \mathrm{O}$ direito de propriedade é assim qualificado pelo Declaração de Direitos do Homem e do Cidadão, cujo art. 17 tem a seguinte redação: 'Como a propriedade é um direito inviolável e sagrado, ninguém dela pode ser privado, a não ser quando a necessidade pública legalmente comprovada o exigir e sob condição de justa e prévia indenização'.

${ }^{5}$ Sobre as incoerências do lema da Revolução Francesa Tobias Barreto (1926), o mais ilustre sergipano, em 1879 escreveu o seguinte: 'Liberdade, igualdade e fraternidade, três palavras que se espantam de se acharem unidas, porque significam três coisas reciprocamente estranhas e contraditórias, principalmente as duas primeiras. (...) Mas Antes de tudo - que a liberdade e a igualdade são contraditórias e se repelem-se mutuamente, não milita dúvida. (...) A liberdade entregue a si mesma, à própria ação, produz naturalmente a desigualdade (...)’.
} 
há muito, o seu caráter social (comunitário), de modo que a transformação da propriedade, de pessoal para comum, restituiria seu aspecto social (MARX et al., 2014). O Manifesto foi escrito em 1848, mas já em 1844 Marx (2010, p. 83) fazia referência a uma "qualidade social" da propriedade.

Contudo, o pensamento de Karl Marx, quanto à propriedade experimentou e ainda experimenta significativa rejeição no mundo ocidental, especialmente pela ideia de supressão da propriedade privada, eleita por ele como ponto central da teoria do comunismo. Em razão disso, a análise desse importante aspecto da propriedade, qual seja, a sua 'qualidade' ou 'papel social', terminou sendo atribuída notadamente às figuras de Émile Durkheim e Léon Duguit.

Durkheim, considerado um dos fundadores da Sociologia acadêmica ${ }^{6}$, tem sua obra As Regras do Método Sociológico apontada como "responsável pela institucionalização da Sociologia como ciência autônoma" (SOLON, 2012). Para ele, tal como as ciências puras (fundamentais), também a Sociologia deveria estar fundamentada em um estatuto metodológico que conferisse caráter de racionalidade científica. 0 objeto da Sociologia seria, destarte, o fato social, que seria "toda maneira de fazer, fixa ou não, capaz de exercer sobre o indivíduo uma coerção exterior; ou ainda, que é geral na extensão de uma dada sociedade que tem existência própria, independente de suas manifestações individuais" (DURKHEIM, 2012).

A partir dessa definição, Durkheim assinala a necessidade de estudo dos fatos sociais como 'coisas', ou seja, como objetos passíveis de delimitação, tal como se dá nas ciências da natureza (física, química, biologia, por exemplo). Essa premissa visaria exatamente a assegurar a possibilidade de investigação racional dos fenômenos sociais, a partir de um método a que se pudesse outorgar cientificidade.

Em sua obra 'Da Divisão do Trabalho Social', Durkheim (2016) sustentou a existência de um princípio da solidariedade social, a partir do qual a existência da própria sociedade estaria condicionada à divisão do trabalho social. Em outros termos, haveria uma divisão do corpo social, estando cada estrutura dotada de uma função elementar e essencial, cujo desempenho adequado terminaria por contribuir para a 'integração geral da sociedade'. E nesse sentido, também o Direito se prestaria a esse fim, exercendo uma função social.

Aproximando o tema ao direito à propriedade privada, que interessa mais de perto ao objeto do presente estudo, é necessário dizer que esse instituto foi historicamente disciplinado por regras de caráter igualmente privado, sobretudo após o Constitucionalismo Moderno, a partir do qual se impôs, por meio de uma Constituição escrita, sérias restrições para o que o Estado interviesse na propriedade dos cidadãos. Nada obstante, Durkheim (2016) questionava a dicotomia histórica do Direito entre público e privado, afirmando que essa delimitação não mais se justificaria. Sobre essa questão, Durkheim (2016) afirmou que

Todo direito é privado, no sentido de que sempre e por toda parte são indivíduos que estão envolvidos e que agem; mas sobretudo todo direito é público, no sentido de que ele é uma função social e de que todos os indivíduos são, ainda que a títulos diversos, funcionários da sociedade.

Nesse mister, Durkheim (2015) refutava o argumento de que a propriedade se constituísse em um direito de caráter absoluto, consistindo, segundo sustentou, apenas na prerrogativa que teria o proprietário

\footnotetext{
${ }^{6}$ A qualificação é atribuída por Santos (2010), que em nota se refere ao livro As regras de método sociológico, sugerindo a conclusão que considera este escrito como o marco inaugural do que que chama sociológica acadêmica.
} 
de retirar a coisa do uso comum (DURKEIN, 2015). Ele afirmava, ainda, que a constituição da propriedade privada decorreria de uma concessão coletiva, estando seu exercício condicionado ao cumprimento de um papel social (DURKHEIM, 2015). Sobre a função social do direito e, em especial, do direito de propriedade, Leon Duguit, contemporâneo de docência de Émile Durkheim na Universidade de Bordeaux, propunha que "A propriedade individual deve ser compreendida como um fato contingente, produto momentâneo de sua evolução social; e o direito do proprietário, como justificado e ao mesmo tempo limitado pela missão social que the incumbe em consequência da situação particular em que se encontra".

Tal como Émile Durkheim, Duguit sustentava a solidariedade como elemento essencial para a existência e subsistência da sociedade, propondo, em decorrência disso, uma transformação na concepção do direito de propriedade consagrado pelo Estado liberal clássico. Destarte, em vez de aceitá-lo como um direito de caráter individual e absoluto, concebia-o como uma função: propriedade-função. Em decorrência disso, o exercício do direito de propriedade estaria condicionado ao cumprimento de uma função social.

Imperioso pontuar que a concepção de propriedade formulada por Duguit terminava por impor a esse direito uma limitação intrínseca․ A função social, por conseguinte, condicionava interna e permanentemente o próprio direito de propriedade, em nada se confundindo, ressalte-se, com eventuais restrições externas. Essa distinção é de extrema relevância em razão em razão de que todas as formulações anteriores reconheciam, em menor ou maior medida, a possibilidade de limitações ao direito de propriedade e ao exercício, como, por exemplo, em decorrência de regras de vizinhança ou, eventualmente, de necessidades imperiosas do próprio Estado.

Embora criticadas, sobretudo pelos que consideravam indevida a possibilidade de a ordem jurídica condicionar intrinsecamente a existência ou o exercício do direito de propriedade, as formulações de Duguit influenciaram significativamente as transformações normativas nesse instituto, algumas destas que, mesmo sem subtrair deste o status de direito subjetivo, impuseram ao seu exercício condicionantes que visariam a conformá-lo aos interesses da sociedade.

No Brasil, o direito de propriedade teve sua trajetória influenciada inicialmente pelos mesmos ideais iluministas que orientaram os movimentos revolucionários do século XVIII. Contudo, até que fosse configurado o atual modelo constitucional, a propriedade experimentou um processo de funcionalização, passando de uma dimensão eminentemente individual, para uma concepção de direito condicionado à observância de interesses da coletividade (ROCHA, 2014; MOTA, 2009). O conhecimento desse itinerário normativo é importante para o tema em estudo, de modo que convém dedicar a essa questão uma seção

\footnotetext{
${ }^{7}$ A questão relacionada à função social ser intrínseca, ou seja, de ela integrar o próprio direito de propriedade é controvertida, embora seja esse o entendimento da doutrina majoritária no Brasil. Conforme consignado no corpo do texto, o pensamento de Duguit apontava para uma função social como uma condição de existência e, mais que isso, de subsistência do direito de propriedade. Nada obstante, essa não foi essa fórmula adotada pela Constituição de 1988, uma vez que, no caput do seu art. 184, ela previu a indenização em razão da desapropriação por interesse social, mesmo para o caso de imóvel rural não cumprir sua função social. Disso se deduz, por óbvio, que o direito de propriedade existiria e subsistiria mesmo sem o cumprimento de sua função social, pois o texto fala em desapropriar e, mais que isso, em indenizar em decorrência da expropriação. Sobre a questão, Dantas (2017) se manifesta no mesmo sentido: Nessa linha, são frequentes as indicações de que o princípio teria passado a ser parte integrante do próprio direito de propriedade. Como consequência, o direito de propriedade deixaria de existir no caso de desrespeito à função social, pois lhe faltaria uma parte decisiva de sua composição. Ainda que a consequência pareça lógica, simplesmente não tem base constitucional. A Constituição de 1988 consagrou o direito à indenização para o caso de desapropriação, cabível na hipótese de descumprimento da função social, o que significa que a Carta considera o direito à propriedade 'completo', mesmo sem o cumprimento da função social. Ou seja, ao contrário daquilo que a doutrina mais progressista entende, a Constituição Federal mostra que a função social da propriedade não é parte integrante do direito de propriedade.
} 
específica.

\section{A propriedade nas constituições brasileiras: funcionalização e ambiente}

Antes de qualquer coisa, importa registrar que o Estado brasileiro foi fundado quando declarada a independência em relação a Portugal, uma vez que, até então, o Brasil apenas integrava os domínios ultramarinos portugueses, inicialmente como Colônia e, após 16 de dezembro de 1815, como componente do Reino Unido de Portugal, Brasil e Algarves. Por essa razão, até 7 de setembro de 1822, o ordenamento jurídico que aqui se aplicava era o mesmo que tinha vigência na Metrópole.

Em consequência do que acima foi asseverado, deduz que nossa história constitucional se principiou com a Carta outorgada de 1824, que acerca do direito de propriedade assinalou o seguinte: Art. 179. A inviolabilidade dos Direitos Civis, e Políticos dos Cidadãos Brasileiros, que tem por base a liberdade, a segurança individual, e a propriedade, é garantida pela Constituição do Império, pela maneira seguinte. (...) XXII - É garantido o Direito de Propriedade em toda a sua plenitude.

Como se vê, no ordenamento jurídico nacional, a primeira disciplina constitucional do direito de propriedade o outorgou, ao menos formalmente, o mesmo status de proteção que foi conferido ao direito de propriedade dos cidadãos franceses por força da Declaração de Direitos do Homem e do Cidadão, tanto que nossa Carta reproduziu quase literalmente o disposto no art. .o daquele diploma estrangeiro.

A propósito da extensão dessa proteção, a simples ausência de qualquer condicionante constitucional ao exercício do direito de propriedade já seria suficiente para conduzir à conclusão de que ele deveria ser considerado, como afirma Miranda (1955), como um direito subjetivo de caráter "absoluto". No entanto, o texto constitucional cuidou de enfatizar essa condição, ao afirmar que a propriedade seria garantida 'em toda a sua plenitude'. A Constituição de 1891, de cunho fortemente liberal, ao menos no seu aspecto formal, manteve a disciplina da propriedade estabelecida pela Carta e 1824, ou seja, tratou-a como direito subjetivo e de caráter individual.

Com o advento da Constituição de 1934, com viés progressista, o exercício do direito de propriedade passou a ter um condicionante expresso no próprio texto constitucional. Embora, tal como as anteriores, tenha conferido ao direito de propriedade a necessária garantia, a Constituição de 1934 estabeleceu que este não poderia 'ser exercido contra o interesse social ou coletivo', remetendo à lei a disciplina relativa aos condicionantes que deveriam informar o regime jurídico da propriedade. Essa disposição constitucional representou um temperamento ao caráter individual da propriedade, na medida em que submeteu um direito, até então eminentemente privado, à observância de preceitos de índole coletiva.

Não durou muito, contudo, essa inovação. Já em 1937, com a outorga da Constituição de 1937, que instituiu o regime de exceção conhecido como 'Estado Novo', foi suprimida alusão no texto constitucional a qualquer condicionante ao exercício do direito de propriedade. Com o final do Estado Novo e a promulgação da Constituição de 1946, o exercício do direito de propriedade volta a ser condicionado ao "bem-estar social".

${ }^{8} \mathrm{O}$ emprego das aspas se justifica em razão do contido na nota de rodapé número 3. 
Além disso, o texto constitucional estabeleceu previsão expressão de que a propriedade privada, mediante processo de desapropriação, poderia ser destinada para fins de reforma agrária.

Embora as fórmulas utilizadas pelas Constituições de 1934 e de 1946, para condicionar o exercício de propriedade, já pudessem ser consideradas como aceitação do pensamento de Durkheim e Duguit, a denominação de 'função social da propriedade' somente foi introduzida na Constituição de 1967, especificamente em seu art. 157, inciso III, no título destinado ao estabelecimento das diretrizes da Ordem Econômica e Social. Disposição idêntica foi mantida na Emenda Constitucional n.o 1, de 1969, mas desta feita no seu art. 160, III, que de igual modo consubstanciava o título destinado à Ordem Econômica e Social. Em ambos os casos, no entanto, nenhuma disposição constitucional tratou de indicar qual seria o conteúdo dessa função social.

A atual Constituição, promulgada em 5 de outubro de 1988, utilizou por 7 (sete) vezes a expressão 'função social', erigindo-a à condição de princípio constitucional de elevado prestígio. A essa conclusão se chega não apenas pela recorrente menção, mas também a partir da análise da disposição topográfica relativa ao primeiro registro dessa expressão no texto constitucional, que figura no mesmo título destinado às garantias e direitos individuais, logo após a referência ao direito de propriedade. $O$ texto constitucional faz, ainda, alusão à função social da propriedade ao disciplinar a Ordem Econômica e Financeira, ao se referir à função social das entidades estatais, bem como ao tratar da propriedade imobiliária urbana e rural.

Para o tema objeto desta pesquisa, entretanto, a mais relevante inovação do atual texto constitucional foi a constante no seu art. 186, inciso II, que estabeleceu como requisito para o cumprimento da função social da propriedade rural a 'utilização adequada dos recursos naturais disponíveis e preservação do meio ambiente'. Essa disposição, embora formalmente constante em dispositivo referente à propriedade rural, estende-se, a partir de uma interpretação teleológica, às demais formas de propriedade. A razão dessa vinculação da função da social da propriedade à proteção ambiental justifica-se na necessidade de adoção de medidas em face da crise ambiental moderna.

A propósito do tema, Leff (2006) assinala que a sustentabilidade se apresenta como "critério normativo para reconstrução da ordem econômica, como uma condição para a sobrevivência humana e para um desenvolvimento durável". Assim, o discurso de sustentabilidade, a partir de uma perspectiva integradora, reforça a necessidade de que a propriedade, como elemento essencial do processo de desenvolvimento, tenha seu exercício informado intrinsecamente pelo aspecto ambiental.

Disso resulta a necessidade de releitura de conceitos, notadamente o de função social, para o fim de aglutinar a este a necessária noção de proteção ao ambiente, num esforço de "internalizar as externalidades ambientais" (LEFF, 2006). Como consequência disso, embora se tenha por certo que a denominação do princípio da 'função social' foi formalmente consagrada pela Constituição, certamente a ideia que dele decorre deve ser considerada como representação material de uma verdadeira função socioambiental da propriedade, o que se conclui pela relação de implicação recíproca que o texto da Constituição de 1988 estabeleceu entre as questões dominais e ambientais. 


\section{CONCLUSÕES}

A propriedade privada, desde sua invenção e ao longo de milênios da história humana, teve diverso estatutos jurídicos. No início de sua regulação pela ordem jurídica, foi considerada como direito de caráter individual e 'absoluto', que conferia ao seu detentor a possibilidade de usar e dispor livremente de determinado bem. A partir de meados do século XIX, com o desenvolvimento da Sociologia, notadamente a partir do conceito de função social, que teve em Émile Durkheim seu maior expoente, ganhou espaço e aceitação a ideia de que todas as estruturas deveriam exercer uma função no corpo social.

Léon Duguit, contemporâneo e colega de Durkheim na Universidade de Bordeaux, desenvolveu suas formulações teóricas sustentando que a existência de imperativos de ordem social impunha transformações no Direito, inclusive no de propriedade, do que resultaria a conclusão de que também este instituto, por alguns considerado como de caráter 'absoluto', deveria também se sujeitar a restrições ditadas por aqueles mesmos imperativos de ordem coletiva. A propriedade privada passou, então, por um processo de funcionalização, uma vez que, se por um lado conferia ao seu titular a possibilidade de dela desfrutar, por outro lhe outorgava o ônus de dar ao seu bem uma destinação que se conformasse aos interesses da sociedade.

Mais recentemente, sobretudo com o agravamento da(s) crise(s) ambiental moderna(s), a questão relativa à sustentabilidade passar a também pautar as discussões relativas à relativização e funcionalização do direito de propriedade, tanto que a própria Constituição de 1988, em seu art. 186, inciso II, estabeleceu que o cumprimento da função social da propriedade se condicionaria à "utilização adequada dos recursos naturais disponíveis e preservação do meio ambiente." Em razão desse novo paradigma, que incrementou as condições do exercício do direito de propriedade para o fim de incluir prescrições de uso sustentável dos bens possuídos, o princípio da função social passa a agregar também o aspecto ambiental como dimensão, além das já tradicionalmente aceitas diretrizes econômicas e sociais (em sentido estrito).

A partir dessa 'nova' feição, tem-se sustentado, com razão, a necessidade de reformulação da própria expressão 'princípio da função social', para o fim de promover a incorporação da dimensão ambiental à própria expressão, passando ele a ser designado de princípio da função socioambiental da propriedade. Mais que uma singela questão de nomenclatura, trata-se de providência de forte caráter simbólico, que se presta a reforçar a importância e a urgência em associar o exercício do direito de propriedade a preocupação com resguardo do ('meio') ambiente.

\section{REFERÊNCIAS}

BARRETO, T.. Um discurso em manga de camisa. Aracaju: ECE, 1926.

BRASIL. Constituição da República dos Estados Unidos do Brasil. In: POLETTI, R.. Constituições brasileiras: 1934. 3 ed. Brasília: Senado Federal, 2012.

BRASIL. Constituição da República Federativa do Brasil. In: TÁCITO, C.. Constituições brasileiras: 1988. 3 ed. Brasília: Senado Federal, 2012.
BRASIL. Constituição do Brasil. In: CAVALCANTI, T. B.; BRITTO, L. N.; BALEEIRO, A.. Constituições brasileiras: 1967. 3 ed. Brasília: Senado Federal, 2012.

BRASIL. Constituição dos Estados Unidos do Brasil. 3 ed. In: BALEEIRO, A.. Constituições brasileiras: 1891. Brasília: Senado Federal, 2012.

BRASIL. Constituição dos Estados Unidos do Brasil. In: 
BALEEIRO, A.; LIMA SOBRINHO, B.. Constituições brasileiras: 1946. 3 ed. Brasília: Senado Federal, 2012

BRASIL. Constituição dos Estados Unidos do Brasil. In: PORTO, W. C.. Constituições brasileiras: 1937. 3 ed. Brasília: Senado Federal, 2012.

BRASIL. Constituição Política do império do Brazil. In: NOGUEIRA, O.. Constituições brasileiras: 1824. 3 ed. Brasília: Senado Federal, 2012.

COULANGES, N. D. F.. A cidade antiga: o estudo sobre o culto, o direito e as instituições da Grécia e Roma. São Paulo. Martin Claret, 2009.

DALLARI, D. A.. A Constituição na vida dos povos: da Idade Média ao Século XXI. São Paulo: Saraiva, 2010.

DANTAS, M. E. C.. Dogmática "opinativa": o exemplo da função social da propriedade. Direito GV, v.13, n.3, p.769795, 2017. DOI: http://doi.org/10.1590/2317-6172201731

DINIZ, M. H.. Código Civil Anotado. São Paulo: Saraiva, 2004 DURKHEIM, É.. As regras do método sociológico. São Paulo: Edipro, 2012.

DURKHEIM, É.. Da divisão do trabalho social. São Paulo: Edipro, 2016.

DURKHEIM, É.. Lições de Sociologia: Física dos costumes e do Direito. São Paulo: Edipro, 2015.

ENGELS, F.. A origem da família, da propriedade privada e do Estado. São Paulo: Centauro, 2002.

HOBBES, T.. O Leviatã. São Paulo: Nova Cultural, 1999.

LEFF, E.. Racionalidade ambiental e reapropriação social da natureza. Rio de Janeiro: Civilização Brasileira, 2006.
LOCKE, J.. Segundo Tratado sobre o Governo. São Paulo: Martin Claret, 2002.

MARX, K.. Manuscritos econômico-filosóficos. São Paulo: Boitempo, 2010

MARX, K.; ENGELS, F.. Manifesto do Partido Comunista. São Paulo: Martin Claret, 2014.

MIRANDA, P.. Direito das coisas: Propriedade. Aquisição da propriedade imobiliária. In: MIRANDA, P.. Tratado de Direito Privado. Rio de Janeiro: Borsoi, 1955.

MOTA, M.. Fundamentos teóricos da função social da propriedade: a propriedade em Tomás de Aquino. In: MOREIRA, E. R.; PUGLIESI, M.. 20 anos da Constituição Brasileira. São Paulo: Saraiva, 2009. p.124-162.

ROCHA, S. L. F.. Intervenção do Estado na propriedade. In: MELLO, C. A. B.; FERRAZ, S. R.; FERREIRA, S. L.; SAAD, A. F.. Direito Administrativo e liberdade: estudos em homenagem a Lúcia Valle Figueiredo. São Paulo: Malheiros, 2014. p.694707.

ROTHER, E. T.. Revisão sistemática X revisão narrativa. Acta Paulista de Enfermagem, São Paulo, v.20, n.2, p.5-7, 2007. DOI: http://doi.org/10.1590/S0103-21002007000200001

ROUSSEAU, J. J.. Do contrato Social. São Paulo: Martin Claret, 2013.

SANTOS, B. S.. Um discurso sobre as ciências. 7 ed. São Paulo: Cortez, 2010.

SEVERINO, A. J.. Metodologia do Trabalho Científico. 24 ed. São Paulo: Cortez, 2016.

SOLON, W.. Apresentação. In: DURKHEIM, É.. As regras do método sociológico. São Paulo: Edipro, 2012.

A CBPC - Companhia Brasileira de Produção Científica (CNPJ: 11.221.422/0001-03) detém os direitos materiais desta publicação. Os direitos referem-se à publicação do trabalho em qualquer parte do mundo, incluindo os direitos às renovações, expansões e disseminações da contribuiç̃o, bem como outros direitos subsidiários. Todos os trabalhos publicados eletronicamente poderão posteriormente ser publicados em coletâneas impressas sob coordenação da Sustenere Publishing, da Companhia Brasileira de Produção Científica e seus parceiros autorizados. Os (as) autores (as) preservam os direitos autorais, mas não têm permissão para a publicação da contribuição em outro meio, impresso ou digital, em português ou em tradução. 